\title{
Diario de campaña de una división republicana desde el nororiente hasta la Costa Caribe colombiana durante las guerras de Independencia. Transcripción documental
}

\author{
Roger Pita Pico 1 iD \\ Academia Colombiana de Historia-Colombia
}

\section{PRESENTACIÓN}

La batalla de Boyacá ocurrida el 7 de agosto de 1819 marcó el inicio del proceso de expulsión definitiva de los españoles durante las guerras de Independencia que se extendieron por más de una década en territorio neogranadino. Aunque la región central y nororiental fue liberada de manera vertiginosa y sin mayores confrontaciones, mucho más dispendiosa y prolongada resultó la lucha en la región de la Costa Caribe y en las provincias del Sur.

Después de aquella crucial batalla, la estrategia de los altos mandos republicanos a la cabeza del presidente Simón Bolívar y del vicepresidente Francisco de Paula Santander consistió en dos frentes, por un lado, la liberación de las zonas de mayor resistencia realista en la Nueva Granada y, por el otro, el alistamiento de la campaña para liberar a Venezuela. Dentro del primero de estos propósitos, se emprendió una intensa labor de reclutamiento y de organización militar teniendo como base los batallones que habían desarrollado la Campaña Libertadora, integrados por militares neogranadinos y venezolanos, a los cuales se sumaron nuevas partidas de conscriptos alentados con el triunfo en los campos de Boyacá.

Para 1820 existían ya en territorio neogranadino un total de 20 batallones $^{2}$. A comienzos de mayo de este año, el Libertador impartió instrucciones precisas al coronel Jacinto Lara ${ }^{3}$ para que marchara hacia Valledupar con el objeto de ocupar a Perijá y cooperar por aquella parte a la liberación de Maracaibo. Lara había quedado en libertad de decidir si mantenía en firme esta campaña por la emancipación de Maracaibo o, si en cambio, se concentraba en la liberación de Santa Marta. Todo dependía del curso de los acontecimientos y de sopesar las ventajas que ofrecieran cada una de estas alternativas.

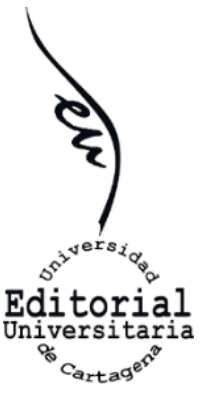

\footnotetext{
${ }^{1}$ Politólogo Universidad de Los Andes, Magíster en Estudios Políticos, Universidad Javeriana. Director Biblioteca "Eduardo Santos" Academia Colombiana de Historia.rogpitc@ hotmail.com

${ }^{2}$ Clément Thibaud, Repúblicas en armas. Los ejércitos bolivarianos en la guerra de Independencia en Colombia y Venezuela, Bogotá, Planeta-Ifea, 2003, pp. 55, 496.

${ }^{3} \mathrm{La}$ amplia trayectoria de este oficial venezolano comenzó en 1810 durante las primeras manifestaciones de emancipación política. Participó en 1813 al lado de Simón Bolívar en la Campaña Admirable y en 1819 en la Campaña Libertadora. Luego de adelantar operaciones en la costa Caribe neogranadina, se trasladó hacia el Sur en donde fue ascendido a General y combatió en las batallas de Bomboná y Ayacucho. Murió en Barquisimeto en 1859. Leonidas Scarpetta y Saturnino Vergara, Diccionario biográfico de los campeones de la libertad de Nueva Granada, Venezuela, Ecuador i Perú, Bogotá, Imprenta de Zalamea, 1879, pp. 251-253.
} 
Para emprender las acciones que le fueron encomendadas, Lara debió marchar inmediatamente hasta la ciudad de Ocaña con el batallón Pamplona debidamente equipado y vestido, y allí debía unírsele la columna del coronel Francisco Carmona y el batallón Rifles que estaba en el cuartel general de la Villa del Rosario. Con el propósito de elevar su pie de fuerza, quedó autorizado para realizar reclutamientos en todo el territorio por donde transitara ${ }^{4}$.

En el marco de la conmemoración del Bicentenario de la Independencia de Colombia, el objetivo de la transcripción documental que se presenta a continuación consiste en mostrar el diario de campaña de las fuerzas al mando del coronel Lara desde su partida del área nororiental de la Nueva Granada hasta la Costa Caribe en el recorrido llevado a cabo desde el 12 de mayo hasta el 12 de agosto de 1820 por las provincias de Pamplona y Santa Marta. Este documento ${ }^{5}$ reposa en el tomo 3 del Fondo Secretaría de Guerra y Marina de la Sección República del Archivo General de la Nación en Bogotá.

Entre las fuentes documentales militares, las cartas y los partes de batalla han sido sin duda las más utilizadas en los trabajos historiográficos. Los diarios de campaña o diarios de operaciones ${ }^{6}$ representan una importante veta de información que desde hace algunos años han sido objeto de mayor interés. Allí se muestra la cotidianidad de los ejércitos en una línea continua de tiempo que permite ver más en detalle el desarrollo de las actividades adelantadas bajo el rigor de la vida militar y las relaciones jerárquicas de poder. Quedan en evidencia en este tipo de documentos el rol asumido por los mandos medios del ejército y el complejo manejo de la tropa, así como también la relación con la comunidad, detalles que no siempre resultaban relevantes para la historiografía tradicional. Se puede observar además otros aspectos como el flujo de tropa, las provisiones y la disciplina militar.

El diario de campaña del coronel Lara revela una información organizada de acuerdo a cuatro variables: los movimientos o marchas de las tropas, las ocurrencias en donde estaban consignados los principales acontecimientos, la instrucción militar de las huestes y, por último, la subsistencia o provisiones diarias de comida.

Cabe precisar que, paralelo al recorrido adelantado por estos contingentes al mando del coronel Lara, se desarrollaban al mismo tiempo dos frentes de operaciones en la región Caribe. El primero de ellos, el más registrado y documentado en relatos históricos, correspondía a la ofensiva naval y terrestre bajo el mando de los oficiales Hermógenes Maza, José María Córdova y

\footnotetext{
${ }^{4}$ Simón B. O’Leary, Memorias del General O Leary, Caracas, Imprenta de la Gaceta Oficial, 1983, tomo XVII, pp. 161167.

${ }^{5}$ Es pertinente aclarar que el documento ha sido transcrito con la ortografía modernizada y se han introducido algunas modificaciones en la puntuación sin alterar el contenido.

${ }^{6} \mathrm{En}$ las fuentes documentales disponibles en archivos, alusivas al periodo de guerra, son en realidad muy escasos los diarios de campaña de la región Caribe pues la mayoría que aún se conservan corresponden a la última fase de la guerra en el Sur, en las provincias de Pasto y Popayán.
} 
Mariano Montilla en la parte baja del río Magdalena y su avance para estrechar el cerco sobre los dos bastiones monárquicos: Santa Marta y Cartagena. El otro frente de operaciones tenía como meta la liberación de la provincia de Riohacha con la ayuda de la Legión Británica ${ }^{7}$.

Tal como quedó consignado en el diario, el batallón Pamplona salió el 12 de julio de Bucaramanga integrado por cuatro compañías. Fue un largo recorrido de más de 150 leguas, a razón de 5 leguas en promedio por día, que siguió en buena parte el camino real que conectaba al nororiente con la costa Caribe y atravesó las poblaciones de Girón, Matanza, Suratá, Cachirí, Ocaña, Río de Oro, Borotaré, San Antonio, El Carmen, San Bernardo, Tamalameque, Algarrobo, Chiriguaná, La Jagua, Hato Chaparro, Becerril, Valledupar, Camperucho, Pueblo Nuevo, María Angola, Piñón y Cerro de San Antonio (Ver Mapa 1).

Mapa 1. Ubicación geográfica del recorrido realizado entre mayo y agosto de 1820 por las fuerzas al mando del coronel republicano Jacinto Lara desde Bucaramanga hasta el Cerro de San Antonio.

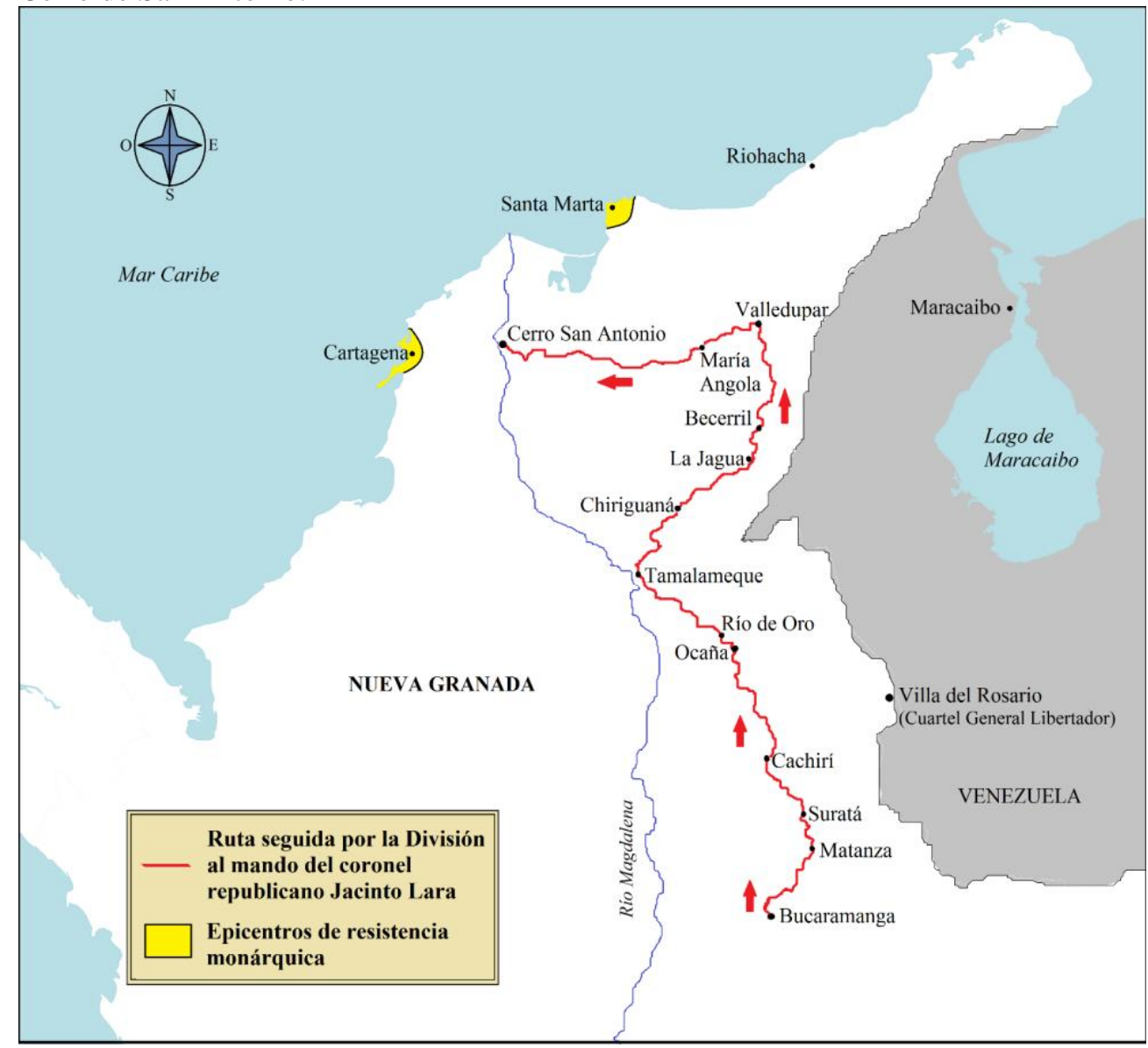

Fuente: elaboración del autor.

\footnotetext{
${ }^{7}$ Véase: Adelaida Sourdís Nájera, "Ruptura del Estado colonial y tránsito hacia la República 1800-1850", en Adolfo Meisel Roca (ed.), Historia económica y social del Caribe colombiano, Bogotá, Ediciones Uninorte-Ecoe Ediciones, 1994, pp. $155-228$.
} 
Esta ruta incluyó una diversidad de espacios geográficos, desde el páramo de Cachirí en donde resultaron "emparamados" 7 militares hasta las ardientes llanuras de la Costa Caribe. En su mayoría, estos trayectos se hallaban poblados por habitantes adversos a la causa republicana y fueron muy pocos los que ofrecieron apoyo irrestricto, como Río de Oro y Cerro de San Antonio. Vale destacar en el documento algunas cortas pero interesantes descripciones sociales, demográficas y económicas de las localidades de tránsito, observándose en algunos parajes la desolación y los estragos de la guerra.

Fue, en términos generales, un recorrido tranquilo, pero al adentrarse a las llanuras costeras comenzaron las escaramuzas y los combates aunque de menor escala, incluyendo una embestida de los indios Tupes en cercanías a La Paz. En Ocaña el batallón recibió algunos refuerzos y se unió a la marcha del batallón Rifles, tal como estaba previsto. Luego en Tamalameque se agregó la columna al mando del coronel Francisco Carmona y finalmente se dio un enfrentamiento militar con algunas partidas enemigas poco después de haber pasado por Chiriguaná. En este punto tuvo lugar una reunión de altos oficiales bajo la dirección del comandante Lara para hablar de estrategia militar y prepararse para la ofensiva que, según se decidió, se haría sobre Santa Marta. Antes de llegar a Valledupar la división se enfrentó a un grupo de 230 militares realistas que fueron batidos. De esta ciudad salió el coronel José María Carreño al mando del batallón Rifles con una columna hacia San Juan en la provincia de Riohacha.

Al acercarse la división al cerro de San Antonio, último destino registrado en el diario de operaciones, el comandante Lara entró en contacto con el coronel Montilla para actuar de manera conjunta con el fin de acentuar la ofensiva contra los españoles resguardados en Santa Marta y Cartagena. Después del recorrido, Lara hizo un balance de su estado de fuerza, contabilizándose 345 hombres en el batallón Rifles, 140 en el de Pamplona, 100 en el de Flanqueadores y 54 de Caballería, para un total de 639 militares activos. En los días siguientes, la tropa siguió a Soledad en donde se dio el encuentro con el coronel Montilla ${ }^{8}$.

El aumento paulatino del pie de fuerza movilizado implicó crecidos esfuerzos oficiales para su sostenimiento, debiéndose recurrir al apoyo de los recursos existentes en los campos, hatos y pueblos y, en algunas ocasiones, a los donativos. La dieta de la tropa era casi siempre pan y carne pero al adentrarse a las sabanas de la Costa Caribe se ampliaron las opciones con plátano, yuca, biscocho y bollos de maíz. Excepcionalmente se contó con otro tipo de raciones compuestas por marranos, chivos e incluso gallinazos. En cercanías a Valledupar se reportó "carne fresca en abundancia". En realidad, la atención a estas tropas fue mucho más favorable de lo que se vivió meses más tarde, tras el recrudecimiento y prolongación de la guerra en esta región costera y

${ }^{8}$ AGN, Sección República, Fondo Secretaría de Guerra y Marina, tomo 3, f. 251v. 
en las zonas del Sur de la República, en donde ya eran críticas las condiciones a causa del hambre, las deserciones y las enfermedades.

En cuestiones de remuneración, todo indica que los soldados rasos no recibieron nada durante estos días pues solo se registró un pago a los veteranos y oficiales. También quedaron indicios de alguna atención religiosa en dos momentos precisos: la bendición de la bandera del batallón a la salida en Bucaramanga y una misa oficiada en un paraje adelante de la ciudad de Ocaña. Con el paso de la marcha se requirió cada vez más atención médica pues, a medida que la tropa se acercaba a los calores inclementes de las sabanas costeras, asimismo empezó a incrementarse el número de enfermos. En total, habían quedado 100 de ellos en Ocaña, 100 más en Tamalameque, 60 en Chiriguaná y 9 en Valledupar ${ }^{9}$.

La disciplina de la tropa fue una de las principales preocupaciones de los altos mandos militares. Un total de 65 desertores fueron reportados durante los dos meses de marcha, llegándose en una sola jornada a registrarse hasta 10 escabullidos. El castigo que les deparaba a estos hombres fue severo pues 5 de ellos fueron sentenciados a pena de muerte a manera de escarmiento. Otros militares fueron ajusticiados "a palos" por cometer robos y otro más recibió sanción por verter palabras "sediciosas". Si se suman las cifras de fugados con las de los desertados y muertos en el camino, se deduce que aproximadamente la división vio menguada en una tercera parte su pie de fuerza.

A lo largo del recorrido, los batallones en marcha recibieron noticias de las operaciones que se adelantaban en otras zonas de la Costa Caribe. A mediados de mayo se supo del arribo de la Legión Británica a Riohacha y el 10 de junio llegaron informaciones sobre el triunfo de Córdova en Magangué. Una noticia extraordinaria, que seguramente causó mucha sorpresa a las fuerzas patriotas en marcha, fue la propuesta española de suspensión de armas para tratar la paz. Aunque esta idea no fue aceptada por el coronel Lara por considerar que era un asunto de exclusiva competencia del general Bolívar, se constituiría en un antecedente para el armisticio que sería firmado a finales de este mismo año en Trujillo. También llegaron noticias que resultaron ser falsas como aquella recibida el 9 de agosto que daba cuenta de que el general Bolívar había batido completamente al general Morillo en Venezuela.

En las semanas siguientes, las fuerzas republicanas fortalecidas con la llegada de nuevos contingentes obtendrían avances militares decisivos pues hacia el mes de noviembre se lograría finalmente la liberación de Santa Marta mientras que Cartagena, erigido como el último bastión monárquico, sería recuperado en octubre del siguiente año luego de un prolongado sitio, con lo cual quedó liberada toda esta región costera.

\footnotetext{
${ }^{9}$ AGN, Sección República, Fondo Secretaría de Guerra y Marina, tomo 3, f. 251v.
} 
El documento aquí transcrito contribuye a llenar algunos vacíos y a presentar una visión más integral de estos tiempos de convulsión política y militar, información que podrá ser complementada y articulada con el intercambio epistolar sostenido por los altos oficiales y gobernantes, así como también con otro tipo de fuentes documentales ${ }^{10}$, con las cuales será posible ofrecer una renovada mirada a esta fase de la guerra en la zona nororiental y costera de Colombia en este crucial año de 1820.

Fuente: Archivo General de la Nación-Colombia, Sección República, Fondo Secretaría de Guerra y Marina, tomo 3, ff. 255r-274r. Año de 1820.

"[folio 255r] Diario de la Columna desde el día 12 de mayo en Bucaramanga hasta la fecha

Movimiento. Ninguno.

Día 12

Ocurrencias. Se fogueó la compañía de Cazadores con dos tiros cada plaza y en fuegos por hileras. Se recibieron órdenes del Ministerio de la Guerra para marchar con la columna, pero al mismo tiempo llegó contraorden del mismo. Instrucción. Se han ejercitado las tropas.

Subsistencias. Pan, carne y sal.

Movimiento. Ninguno.

Ocurrencias. Se fogueó parte del batallón. Se recibieron órdenes del Ministerio de la Guerra para ponerse en marcha para Ocaña con el batallón. Inmediatamente se dieron las órdenes del coronel [Pedro] Fortoul, las diligencias precisas para cobrar las deudas de los asentistas de aguardiente de este departamento para socorrer la tropa. Se mandó comisión a Girón para comprar todos los géneros que allí hubiera para vestido del batallón.

Instrucción. La misma.

Subsistencia. La misma.

Movimiento. Ninguno.

Ocurrencias. Se ha fogueado parte del batallón. Vinieron dos partidas pequeñas de reclutas para el batallón. Se recibieron las instrucciones que deben observarse en la marcha, remitidas por el Ministerio de la Guerra.

Instrucción. La misma.

Subsistencia. La misma.

Movimiento. Ninguno.

[f. 255v] 15

Ocurrencias. Se han tomado de Girón y Pie de la Cuesta todos los géneros blancos y azules para hacer vestido para la tropa. Se encargó al ciudadano

${ }^{10}$ Véase por ejemplo la narración de un militar anónimo inglés durante la fase final de este recorrido. Isidro Vanegas, Las batallas de Boyacá: hombres, mujeres, experiencias, Tunja, Ediciones Plural, 2019, pp. 78-83. 
Francisco Montaña de la hechura de las camisas y el género de calzones se entregó al ciudadano Jones para mandarlo a cortar.

Instrucción. La misma.

Subsistencia. La misma.

Movimiento. Ninguno.

Ocurrencias. Han llegado de los pueblos siete reclutas y se desertaron tres del batallón Pamplona. Se recibieron duplicados de los oficios del Ministerio de la Guerra y un parte del señor coronel [Francisco] Carmona en que anuncia haber llegado al Río Hacha la expedición Irlandesa y que obra sobre Santa Marta. Se mandaron y duplicaron comisionados para recoger los bagajes para la marcha. Se previno al mayor Delgado siguiera una información sumaria contra el capitán Ortiz, que por haber vertido palabras sediciosas, se halla preso en el principal. Llegó el capitán Herrera destinado al batallón Pamplona, y se le mandó dar colocación.

Instrucción. Se trabajó con mucho esmero enseñando al batallón el manejo de armas.

Subsistencia. La misma.

\section{7}

Movimiento. Ninguno.

Ocurrencias. Se fogueó el resto del batallón que estaba sin foguearse. Llegó de Pamplona el señor coronel Fortoul y de acuerdo con el señor coronel [Jacinto] Lara dio órdenes muy estrechas a fin de conseguir los bagajes necesarios para la marcha. [f. 256r] Llegaron ocho reclutas de Cácota de Suratá. Se castigó un soldado con 50 palos por ladrón.

Instrucción. La misma.

Subsistencia. La misma.

Movimiento. Ninguno.

Ocurrencias. Llegaron 17 mulas traídas por el alcalde de Girón de las pedidas para la marcha.

Instrucción. La misma.

Subsistencia. La misma.

Movimiento. Ninguno.

Ocurrencias. Han llegado quince reclutas de los pueblos. Se hicieron llevar a la armería todos los fusiles descompuestos para componerlos. Se han hecho empaquetar las lanzas y los vestuarios para tenerlos listos para la marcha. Se nombró de comisario de la columna al ciudadano José Antonio Valdivieso, entregándole en el momento todos los fondos que estaban destinados para ella. Se mandaron pagar las plazas veteranas del batallón y los oficiales, dando a estos media paga en cuenta de sus sueldos devengados hasta que remitan del cuartel general los casos de cada uno para hacer el ajuste. 
Instrucción. La misma.

Subsistencia. La misma.

Movimiento. Ninguno.

Ocurrencias. A las 6 de la mañana se bendijo la bandera del batallón y se juramentó la tropa con todas las formalidades de Ordenanza ${ }^{11}$. Llegó una partida de 57 reclutas de Málaga. Se dio la orden para marchar mañana y se tomaron todas las providencias para verificarlo.

[f. 256v] Instrucción. La misma.

Subsistencia. La misma.

21

Movimiento: Marchó la columna a las 9 de la mañana, caminó tres leguas por camino seco y muy pedregoso y se campó en el sitio de Corral de Piedra a donde llegó a las cuatro de la tarde.

Ocurrencias. Se pasaron por las armas dos desertores aprehendidos antes de marchar. Se levantaron sobre 80 cargas del parque, parte en mulas, parte en costilla de maleteros. Se quedaron cinco individuos con tres fusiles y con las municiones. No hubo novedad en la noche.

Instrucción. La misma.

Subsistencia. La misma.

22

Movimiento. A las 6 de la mañana marchó la columna, anduvo cinco leguas por buen camino aunque pedregoso y a las dos de la tarde llegó a la parroquia de Matanza donde se acuarteló. Se desertó un soldado con fusil, fornitura y munición y se aprehendió otro que intentó fugarse en el camino. Hubo ocho altas en el batallón.

Instrucción. La misma.

Subsistencia. Sal, pan y carne.

23

Movimiento. A las 7 de la mañana siguió el batallón su marcha hasta Suratá en donde llegó a las 10 del día después de dos leguas de marcha. Se pasó lista en Suratá e inmediatamente se siguió la jornada y a las dos horas de marcha llegó a la casa llamada de Pedro Alonso. Allí se dividieron las compañías en diferentes campamentos, unos inmediatos a otros.

Ocurrencias. Se pasaron por las armas dos desertores que se aprehendieron [257r] en la Matanza y se perdonó otro condenado a la misma pena por consideración a ser soldado veterano muy antiguo pero se castigó al frente de su compañía con 50 palos. Se racionó la tropa de sal para cuatro días. Se recibieron 200 pesos de Cácota de la Matanza y se entregaron en comisaría.

\footnotetext{
${ }^{11}$ Reglamento para la organización y funcionamiento del estamento militar. Las primeras Ordenanzas fueron promulgadas en el siglo XV en España y algunas de sus normas fueron retomadas por el gobierno republicano.
} 
El camino de esta jornada es bueno, no hay qué comer y la marcha de todo el día fue de tres y media leguas.

Instrucción. Ninguna.

Subsistencia. Pan, carne y sal.

\section{4}

Movimiento. A las 7 de la mañana continuó su marcha el batallón hasta Cachirí. Allí se pasó lista y se campó por compañías, mandando la de Cazadores y la $1^{\mathrm{a}}$ al pie del páramo bajo la responsabilidad del ayudante mayor, y la segunda a una casita que está a un cuarto de legua antes del páramo, bajo la de su comandante. La $3^{\mathrm{a}}$ y $4^{\mathrm{a}}$ se alojaron en la misma casa de Cachirí.

Ocurrencias. Dio parte el batallón de faltar cinco hombres. Se alojó el parque y la comisaría en el Alto de Cachirí. Se racionó la tropa de biscocho hasta llegar a Ocaña y se recibieron del comisionado de Cachirí dos reses pertenecientes al Estado. Se tomaron las precauciones necesarias para que en la noche no hubiera deserción. El camino es bueno y solo un poco quebrado y no hay auxilio de ninguna especie con este lugar. Se pueden campar en el Alto 600 hombres. La jornada de este día ha sido de cuatro y media leguas.

\section{5}

Movimiento. A las cuatro de la mañana se pusieron en marcha las dos compañías campadas en la casa de Cachirí y el parque y comisaría, y a poco rato de marcha llegaron aquellas al lugar donde estaban las otras que aún no habían marchado sin embargo de tener orden desde el día anterior para hacerlo [f. 257v] muy temprano, teniendo la deserción que podría haber en el camino por la oscuridad de la mañana. Luego que se reunió el batallón, se esperó al pie del páramo de Cachirí que amaneciera y a las $51 \frac{1}{2}$ se puso en marcha. A la media hora se entró en el páramo y redoblando la marcha todo lo que permitía la fragosidad del camino, llegamos a la ranchería del Moán a las tres de la tarde, quedándose atrás más de la mitad del batallón, el parque y comisaría. Se destinaron los lugares en que debía camparse éste por compañías, siendo al raso.

Ocurrencias. Se emparamaron tres de los conductores del parque y cuatro soldados del batallón. Faltaron en este 30 hombres pero, sea que estaban atrasados por cansados o sea algún otro motivo, han ido viniendo y la falta ha quedado resarcida a solo 20 hombres. La guardia de prevención aprehendió un desertor que se había fugado en el páramo. Quedaron atrasadas nueve cargas de alpargates de la comisaría, y la tropa y arrieros han salido muy estropeados del páramo, en donde se han cansado muchas bestias del parque y comisaría. El camino es malísimo y donde campamos escasamente se puede campar el batallón. La jornada ha sido de cinco leguas.

Instrucción. Ninguna.

Subsistencia. Se racionó la tropa con carne fresca. 


\section{6}

Movimiento. A las 7 de la mañana marchó el batallón reunido hasta Cáchira a donde llegó a las cuatro de la tarde, quedándose atrasados algunos soldados. Se movió el parque a la misma hora que el batallón y llegó al lugar del campamento a las 7 de la noche. Se atrasó parte de la comisaría.

Ocurrencias. Antes de marchar el batallón se pasó por las armas a un desertor aprehendido el día anterior en el páramo. Hubo seis deserciones en todo el batallón. [f. 258r] El camino es de subidas y bajadas muy grandes, hay mucha piedra y la jornada ha sido de cinco leguas. En la mitad de la jornada hay un terreno llano donde se pueden campar 1.500 hombres, y en él hay dos casitas pequeñas y dos regulares, todas están abandonadas.

Instrucción Ninguna.

Subsistencia. Carne fresca.

27

Movimiento. A las 10 de la mañana marcharon dos compañías al sitio de Ramírez. Las otras tres quedaron en Cáchira esperando unas cargas que se habían atrasado y que debían repartirse en ellas. A las 12 del día llegaron las cargas, se repartieron en las compañías y marcharon también a Ramírez. El señor coronel Lara se quedó en Cáchira para marchar bien temprano al otro día a reunirse con el batallón.

Ocurrencias. Se dejó al comisario en Cáchira con 58 bestias descansando, y el parque siguió todo a costillas, completando el número de cargadores con soldados del batallón y prometiendo a estos que serían gratificados. Hubo cinco deserciones. La jornada ha sido de una legua, el camino muy malo y muy barrealoso, y el lugar del campamento muy incómodo y ___ ${ }^{12}$.

Instrucción. Ninguna.

Subsistencia. La misma.

28

Movimiento. A las 4 de la mañana marchó el señor coronel a reunirse al batallón y lo efectuó a las 6; poniéndose a esta hora en marcha dicho cuerpo hasta un lugar llamado los Encantos a donde llegó a las cinco de la tarde.

Ocurrencias. Llegó el parque un poco después que el batallón. Se campó este por compañías haciendo responsable a cada comandante de la suya. Se encontraron en este sitio 10 muchachos que se agregaron al batallón. El camino es muy malo y casi intransitable, con callejones muy profundos y angostos, y subidas y bajadas muy pendientes y peligrosas. La jornada ha sido de cinco y media leguas. [f. 258v] En el lugar del campamento hay una casita vieja abandonada. No hay recursos en el tránsito y no se encuentran casas ni gente.

Instrucción. Ninguna.

Subsistencia. La misma.

${ }^{12}$ Esta línea es la señal usada por el transcriptor para indicar algunas palabras ilegibles en el documento. 


\section{9}

Movimiento. A las 8 de la mañana marchó el batallón y el señor coronel se adelantó al pueblo de La Cruz a prevenir lo necesario para él.

Movimiento. Ninguno.

Ocurrencias. Llegó el batallón a las 12 del día, se alojaron las compañías en diferentes cuarteles y se racionaron todas. Se entregaron a los alcaldes las bestias que había para que las pusieran en un potrero. Se mandó limpiar el armamento. Se dieron de alta 22 reclutas y hubo nueve deserciones. Se recorrió todo el batallón excepto los oficiales con cien pesos. Se aprehendió un desertor.

Instrucción. Ninguna.

Subsistencia. Carne y pan.

Movimiento. Ninguno.

Ocurrencias. Se limpió el armamento.

Instrucción. Ninguna.

Subsistencia. Carne y sal.

Junio $1^{\circ}$

Movimiento. A las ocho de la mañana se puso en marcha el batallón Pamplona para Ocaña.

Ocurrencias. Se prepararon víveres para el batallón de Rifles de la Guardia que según oficio que se ha recibido del señor coronel [José María] Carreño llegará mañana a sus órdenes. Se previnieron [f. 259r] cuarteles para el mismo batallón.

Instrucción. Ninguna.

Subsistencia. Ninguna.

Movimiento. Ninguno.

Ocurrencias. Llegó el batallón de Rifles a este pueblo a las ocho de la mañana al mando del señor coronel Carreño con 520 plazas y muy buena tropa. Se alojaron las compañías en cuarteles diferentes. El señor coronel Carreño trajo comunicaciones reservadas de Su Excelencia el Libertador [Simón Bolívar] para el señor coronel Lara. Éste ha sido nombrado comandante general de la División que se va a formar de Rifles, Pamplona y la columna del señor coronel Carmona cuando se reúna a esta, la cual está obrando por la provincia de Santa Marta.

Instrucción. Ninguna.

Subsistencia. Carne, sal y algún socorro en dinero.

Movimiento. Ninguno. 
Ocurrencias. A las 7 de la mañana se puso en marcha el señor comandante general para Ocaña, dejando al coronel Carreño la orden de que marchara el batallón al mediodía. Esta jornada es de seis leguas, de camino muy bueno y llano. A las 11 del día llegó a Ocaña preparando todo lo necesario para el batallón Rifles.

Instrucción. Se ejercitó el batallón Pamplona dentro de sus cuarteles.

Subsistencia. Carne, sal, plátanos y raíces.

Movimiento. Ninguno.

Ocurrencias. Llegó el batallón Rifles a las 10 de la mañana y se alojó en un solo cuartel muy grande. Se alojaron igualmente los señores oficiales en las casas particulares de la ciudad. Hay vecinos de ella muy enemigos de la causa y otros son patriotas. La ciudad es grande [259v] y cómoda pero tiene muy pocos recursos y los que se encuentran son de los pueblos dependientes de ella. Hay también muy poca riqueza en los vecinos.

Instrucción. Se ha ejercitado solo el batallón Pamplona.

Subsistencia. La misma.

Movimientos. Ninguno.

Ocurrencias. Se pasó revista de armas al batallón de Rifles. Se ordenó componer el armamento descompuesto de los batallones.

Instrucción. La misma.

Subsistencia. La misma.

6

Movimiento. Ninguno.

Ocurrencias. Se pasó revista de armas. Se nombró Juez de Secuestros y Tesorero de esta ciudad y su jurisdicción al ciudadano Pedro Ribón. Se dio a reconocer al señor coronel Carabaño por comandante de la columna que forman los batallones Rifles y Pamplona y al mayor [Manuel María] Obregón por mayor de ella.

Instrucción. Se ha ejercitado el batallón Pamplona de mañana y tarde.

Subsistencia. Carne, pan y sal.

7

Movimiento. Ninguno.

Ocurrencias. Se reconoció al señor coronel [Miguel] Figueredo por comandante de la plaza y departamento, a cuyo destino vino por orden de $\mathrm{Su}$ Excelencia. Se dio una proclama de indulto a los pueblos y sus habitantes. Se pasó revista de municiones.

Instrucción. La misma.

Subsistencia. La misma.

Movimiento. Ninguno. 
Ocurrencias. Se trabaja en prevenir lo necesario para continuar la marcha. Llegaron de los pueblos 26 mulas de cuenta de mayor número que se ha pedido para el parque.

Instrucción. La misma.

[f. 260r] Subsistencia. La misma.

Movimiento. Ninguno.

Ocurrencias. Se comisionó al señor cura de esta ciudad para recoger de los sacerdotes un donativo señalado de 1.900 pesos para socorrer las tropas. Se siguen preparando todo para la marcha. Se desertaron seis hombres de la guarnición.

Instrucción. La misma.

Subsistencia. La misma.

Movimiento. Ninguno.

Ocurrencias. Se han desertado seis individuos del batallón Pamplona. Ha habido 24 altas en el de Rifles. De todo el donativo se han recogido 600 pesos. Se ha recibido comunicación del comandante [Hermógenes] Maza e incluye la noticia de la victoria del teniente coronel [José María] Córdova sobre el enemigo por Magangué. Se han montado 25 hombres del batallón Rifles al mando del capitán

Instrucción. La misma.

Subsistencia. La misma.

Movimiento. Ninguno.

Ocurrencias. Se ha recibido comunicación del señor coronel Carmona, incluyendo la correspondencia interceptada al enemigo de Cartagena. Se han montado siete hombres más de Rifles. Ha habido ocho altas en el mismo batallón y se han desertado dos del de Pamplona.

Instrucción. La misma.

Subsistencia. Carne, pan y sal.

Movimiento. Ninguno.

Ocurrencias. Se trabaja incesantemente en la armería y demás maestranzas y se prepara todo para marchar dentro de dos a tres días.

[f. 260v] Instrucción. Ninguna.

Subsistencia. La misma.

Movimiento. Ninguno.

Ocurrencias. Se han dado las órdenes convenientes para marchar pasado mañana y se ha pedido el ganado y bagajes necesarios al efecto.

Instrucción. Se han ejercitado los batallones. 
Subsistencia. Pan, carne y sal.

14

Movimiento: Ninguno.

Ocurrencias. Se han entregado al señor coronel Figueredo mil cartuchos y 200 piedras de chispa y 30 fusiles. Se ha puesto todo muy pronto para marchar mañana. Ha habido tres deserciones en el batallón Pamplona.

Instrucción. La misma.

Subsistencia. La misma.

15

Movimiento. A las 10 de la mañana se puso en marcha la columna, llevando cubierta la vanguardia con 25 hombres, en seguida el batallón Rifles, después [el batallón] Pamplona y el gran parque y en la retaguardia la Caballería. Caminamos legua y media por muy buen camino y llegamos al pueblo de Río de Oro a las 12 del día en donde se dio cuarteles a la tropa.

Ocurrencias. Se tomaron medidas para precaver la deserción y se cubrieron los caminos con avanzadas de Caballería. Este pueblo es muy patriota, tendrá como cien casas y no hay en él de qué subsistir.

Instrucción. Ninguna.

Subsistencia. Pan, carne, plátano y sal.

16

Movimiento. A las 7 de la mañana se puso en marcha la División con una descubierta como el día anterior. Siguió Rifles, Pamplona y la Caballería. Marchamos por muy buen camino hasta el pueblo de Borotaré habiendo caminado dos leguas y media. Pasamos por el de San Antonio. Se camparon las tropas por compañías por ser muy pequeñas las casas. La Caballería siguió a separarse un poco más adelante del pueblo junto del mismo camino que debíamos llevar por la mañana. El parque se [f. 261r] puso en los pretiles de la iglesia cubierto con unos toldos.

Ocurrencias. Se tomaron las precauciones anteriores. Llovió un poco en la prima noche. El pueblo pequeño y miserable, sus vecinos tienen algunos $\operatorname{conucos}^{13}$.

Instrucción. La misma.

Subsistencia. La misma.

17

Movimiento. Siguió la columna a las 61/2 de la mañana. La Caballería marchó adelante y las demás tropas en el mismo orden anterior sin descubierta. El camino de esta jornada es muy bueno hasta la parroquia del Carmen a donde llegamos a las 121/2 del día habiendo marchado tres leguas. En el camino hay algunas casas habitadas y abandonadas y una hacienda regular de caña y plátanos. El pueblo nos recibió con mucho entusiasmo por su exaltado patriotismo. Hay en esta marcha que pasar 39 veces una quebrada. La tropa

${ }^{13}$ Parcela pequeña de tierra dedicada al cultivo. 
se acuarteló como antes, el parque se pasó en una buena casa de teja y la Caballería pasó a dormir a una hacienda de cacao y plátanos, con una buena casa y dos o tres más pequeñas en las cuales se pueden alojar dos mil hombres. El pueblo tendrá poco más o menos cien casas, entre ellas algunas buenas.

Ocurrencias. Se recibieron a las dos de la mañana oficios del señor coronel Carmona fechados en Chiriguaná en que anuncia que en aquel pueblo se dice que el señor coronel [Mariano] Montilla derrotó en Rio Hacha con la expedición Irlandesa al enemigo en número de dos mil hombres. Se le participó al señor coronel Carmona que por orden de Su Excelencia estaba él destinado a mandar la segunda columna que se componía del batallón Flanqueadores y toda la Caballería.

Instrucción. Se han ejercitado los cuerpos.

Subsistencia. Pan, plátanos, carne y tres panelas a cada plaza.

18

Movimiento. Se puso en marcha la División después de haber asistido a la misa a las 6 y marchamos cuatro leguas hasta el sitio del Gobernador. El camino es muy bueno pero hay que pasar 19 veces una quebrada.

Se campó la columna en una sabana de más de dos leguas en cuadro. El batallón Pamplona formado en columna con centinelas en los flancos y los oficiales en sus puestos para precaver la deserción. Se recibió del señor coronel Carmona la confirmación de la derrota de los enemigos anunciada ayer.

[f. 261v] Instrucción. Ninguna.

Subsistencia. Ninguna.

19

Movimiento. A las 6 de la mañana se puso en marcha la División por camino de sabana hasta el pueblo de San Bernardo en donde se campó a las 3 de la tarde, alojándose por compañías en las casas del pueblo. La jornada ha sido de cuatro leguas.

Ocurrencias. Se reclutaron aquí ocho hombres y se ofició al señor coronel Carmona para que no comprometiera acción con el enemigo. El pueblo es más miserable y sus habitantes están casi desnudos.

Instrucción. Ninguna.

Subsistencia. Carne y bollos de maíz.

20

Los cuerpos empezaron su marcha a las 7 de la mañana y a las 12 del día llegaron al Hato de Sabana Larga. Aquí detuvimos dos horas mientras hacía remedios la columna. Antes de llegar a este sitio, se recibió un parte del señor coronel Carmona fechado en Tamalameque en que dice haberse retirado de allí porque se presentó el enemigo a tres leguas de distancia de su cuartel en número superior a sus fuerzas, y que por cálculo serán 1.200 hombres inclusos 100 de Caballería, casi toda la fuerza de línea, pero él no se retiró hasta no examinarla bien. En el momento se apuraron los ranchos y seguimos la marcha hasta un trapiche a dos leguas de Tamalameque a donde llegamos a 
las cinco de la tarde marchando por muy buenos caminos y después de 51/2 leguas de jornada.

Ocurrencias. Al salir de una montaña pequeña que está antes de llegar al campamento, encontramos con el señor coronel Carmona que venía solo a encontrar al señor comandante general de la División. Estos jefes se separaron del camino a tratar asuntos reservados concernientes a la situación presente. Los cuerpos se camparon formados en columna cerrada en masa y con distancia de diez pasos, uno de otro. El parque se situó a la izquierda de la División custodiado por 25 hombres. Se cubrió el campo.

Instrucción. Ninguna.

Subsistencia. Pan y carne.

\section{1}

Movimiento. Ninguno en la División. El señor comandante general con su ayudante marchó al pueblo de Tamalameque con el fin de activar la marcha de la columna del señor coronel Carmona [f. 262r] a reunirse con la del señor coronel Carreño y con el objeto de hablar con el comandante de marina y con el del pueblo sobre los equipajes, parques, comisaría y enfermos que debían remitirse allí. Hizo el señor coronel estas diligencias y se volvió al campamento a las 12 del día.

Ocurrencias. Se remitieron las cosas dichas al pueblo al cargo de dos oficiales con el fin de desembarazar la columna que está puesta desde este momento en disposición de batirse. Se acabaron de municionar el batallón Rifles a 40 cartuchos y el de Pamplona a 30. A las dos de la tarde llegó la columna del señor coronel Carmona compuesta de 70 hombres de Caballería y 200 de infantería, viniendo este cuerpo también municionado, y aquel regularmente montado. A las cinco de la tarde cayó una abundantísima lluvia que obligó a meter los batallones a la casa del lugar para preservar el armamento. Sosegó el tiempo a las 6 e inmediatamente se pasó lista a la que faltaron cuatro de Pamplona y dos [de] Flanqueadores que se aprovecharon de la lluvia para desertarse. El mayor Obregón se destinó a Tamalameque de comandante mientras estuviesen allí los efectos pertenecientes a la División para que cuide de ellos.

Instrucción. Ninguna.

Subsistencia. Pan y carne.

\section{2}

Movimiento. A las 7 de la mañana marchó la División del modo siguiente: la Caballería llevaba la vanguardia, seguía la primera columna, luego el parque se dejó y el batallón Flanqueadores cubría la retaguardia. Por sabanas y algunas cejas de monte pequeñas caminamos tres leguas y media hasta las tres de la tarde, a cuya hora llegamos al hato de Buenavista. Se campó la División por batallones en columna cerrada para pasar así la noche.

Ocurrencias. Se cogió ganado en este hato en donde no faltan cuatrocientas reses. Se mandó un negro de espía sobre los enemigos o para que desde Algarrobo mandara algunas mujeres a este fin.

Instrucción. Ninguna. 
Subsistencia. Pan y carne.

23

Movimiento. Seguimos la marcha a las 5 de la mañana y en el mismo [f. 262v] orden del día anterior. Caminamos también por sabana hasta el Hato de Caracolí. Al llegar aquí se oyeron algunos tiros de fusil e inmediatamente se recibió parte de que había una partida enemiga allí. Hizo el señor comandante general adelantar la $1^{\mathrm{a}}$ compañía de Rifles haciéndola cargar de firme sobre la marcha. Al llegar la compañía ya se había retirado la partida enemiga por los bosques pues solo eran 40 hombres, y parece que venían a coger ganado al hato. Siguió inmediatamente todo el batallón y llegó al lugar a las 11 del día en donde campó como el día anterior, siendo de 31/2 leguas la jornada.

Ocurrencias. Se mandaron los carabineros a examinar el enemigo, y en la noche se recibió parte de aquellos de que se había retirado este a Chiriguaná. Se cubrió el campo.

Instrucción. Ninguna.

Subsistencia. Carne.

24

Movimiento. Se siguió la marcha a las $5 \frac{1}{2}$ de la mañana llevando a la vanguardia la $1^{a}$ compañía de Rifles como descubierta a poca distancia el batallón, y cubriendo la retaguardia de este la Caballería. Seguía el batallón Pamplona y luego Flanqueadores, encargado este de la custodia del parque. A las 8 de la mañana llegamos al Algarrobo, se hizo un pequeño alto para la reunión de los cuerpos y entramos en la montaña a poco rato después, dejando el camino común a la izquierda y tomando una trocha que nos debía conducir al lado abajo del pueblo. Al salir de la montaña que tiene poco más de tres leguas y de muy mal camino, encontró la $1^{\mathrm{a}}$ compañía con ocho a diez hombres que huyeron inmediatamente, se les hizo fuego para detenerlos pues se escaparon al furor del momento. Salimos a la sabana a las dos de la tarde por la derecha del pueblo de Chiriguaná y a una legua de distancia de él avistamos una mujer que fue aprehendida inmediatamente y nos impuso hallarse el enemigo [f. 263r] en el bosque del Contrabando fuera del pueblo tomando el camino del Valle Dupar. Esperamos un poco la reunión del resto de los batallones y mientras tanto se mandó reconocer con unos carabineros al enemigo. En este momento cayó una fuerte lluvia pero afortunadamente cesó luego. Después que se reunieron los batallones formamos en columnas por compañías y marchamos sobre el enemigo que se hallaba apoyado al bosque. Luego que este nos divisó, desplegó una compañía en guerrilla sobre nosotros para dar lugar a que el jefe que los mandaba observara bien nuestra fuerza. Inmediatamente desplegó media compañía de la $1^{\text {a }}$ sobre la del enemigo, y esta se retiró luego que la nuestra rompió el fuego hacia el bosque en que estaba el resto de la fuerza que, al parecer o según lo que veíamos, serían solo 300 hombres. Se reforzaron nuestras guerrillas con el resto de la compañía y alguna caballería y empezaron los enemigos la retirada sostenida por 50 hombres de caballería españoles. Se auxilió la $1^{a}$ compañía con la $2^{a}$ para la persecución ayudada también de la caballería pero la enemiga, 
retirándose siempre por entre el bosque protegiendo su infantería, nos impedía poder cargar de firme sobre ellos. Seguimos persiguiéndolo legua y media de tal modo que aunque no pudimos matarle ni tomarle ningún prisionero, le dispersamos y pusimos en fuga toda la infantería llevando en la última retirada solo como 100 hombres. La noche empezaba ya a cerrar y una grandísima lluvia nos amenazaba. Nos retiramos por estos motivos al pueblo por el camino por donde se retiró el enemigo y llegamos a las 61/2. La tropa tomó cuarteles y cayó el agua.

Ocurrencias. Las dichas.

Instrucción. Ninguna.

Subsistencia. La tropa tomó chivos, marranos y gallinazos.

\section{[f. 263v] 25}

Movimiento. Salió al amanecer una partida gruesa de caballería muy bien montada a perseguir al enemigo.

Ocurrencias. El señor comandante le hizo cargos al señor coronel Carmona de cómo había dado parte de que el enemigo constaba de 1.200 hombres y solo habían aparecido como 300, contestó que los habrían licenciado, y que se afirmaba en que habían venido sobre él las tropas que anunció en su parte. Se presentó un soldado de los que estaban ayer con el enemigo y dice que no llevan sino como 100 hombres y que la fuerza que se presentó era toda la que había venido sobre el coronel Carmona. Este fue el motivo por [el] que el señor comandante general no avanzó sobre el enemigo ayer con todo su cuerpo ligero y la caballería, pues creía que aquel constaría de 1.200 hombres. Se limpió un poco el armamento. Se mandó venir el parque, equipajes y enfermos alentados de Tamalameque y se mandó una caballería para custodia. Instrucción. Se han ejercitado las tropas.

Subsistencia. Carne de ganado y marranos.

Movimiento. Ninguno.

Ocurrencias. Se han mandado partidas en busca de pan para las tropas y se hacen todos los esfuerzos posibles para saber del enemigo.

Instrucción. La misma.

Subsistencia. Yuca, maíz y carne.

Movimiento. Ninguno.

Ocurrencias. Se ha recibido parte de la caballería que fue sobre el enemigo, de que no lo ha podido alcanzar pues [f. 264r] va a marcha redoblada. Se pasó revista de armas con toda la División. Se han presentado algunos vecinos.

Instrucción. La misma.

Subsistencia. La misma.

28

Movimiento. Se puso en marcha la caballería del señor coronel Carmona para el Hato de La Jagua con el objeto de vigilar y saber del enemigo. 
Ocurrencias. Se siguen presentando gente del pueblo y se enferma mucho la tropa. Ha habido una alta en el batallón Rifles y ocho bajas en el de Pamplona. Se recibió comunicación del señor coronel Montilla por el señor comandante Córdova, y dice está fondeado con la escuadra en Sabanilla y que las tropas están a bordo.

Instrucción. La misma.

Subsistencia. La misma.

Movimiento. Ninguno.

Ocurrencias. El señor coronel Carmona ofició pidiendo permiso para pasar al Chaparro por estar allí la columna mejor situada y para batir una guerrilla que se está formando. Se le concedió todo en el concepto de que él conoce mejor el país. Se ofició al señor coronel Montilla y se le remitieron las órdenes e instrucciones de Su Excelencia. Se ofició por duplicado al Ministerio de la Guerra. Los oficios para el señor coronel Montilla fueron dirigidos por el conducto del señor comandante Córdova. Se supo que el mayor Obregón se había puesto en marcha con el parque y equipajes por agua para aquí.

Instrucción. La misma.

Subsistencia. La misma.

Movimiento. Ninguno.

Ocurrencias. Se incorporó un recluta del batallón Rifles. Se aumenta [f. 264v] el hospital considerablemente con las enfermedades en él sobre 80 hombres. Se sigue presentando la gente del pueblo. Este es muy enemigo del sistema. Se encontró en el monte muerto por los del mismo pueblo un asistente del capitán White que fue por pasto, de una lanza y dos machetazos.

Instrucción. La misma.

Subsistencia. La misma.

Movimiento. Ninguno.

Julio $1^{\mathrm{o}}$

Ocurrencias. Pasaron revista de armas y municiones las dos primeras compañías de Rifles y se dio la orden para que al salir las otras dos que estaban de servicio lo hicieran igualmente. Se sigue presentando la gente del pueblo, la cual huye mucho de servir. El pueblo tendrá unas 40 casas, hay muchas mujeres ya presentadas pero solo como 20 hombres pues están todos en los montes.

Instrucción. La misma.

Subsistencia. La misma.

Movimiento. Ninguno.

Ocurrencias. Llegaron de Ocaña para Tamalameque los ciudadanos N. Cuéllar y Marcelo Álvarez. Llegó también el capitán Cárdenas conduciendo un botiquín desde Bogotá. Da por noticia que desde el 30 que salió de 
Tamalameque se embarcó el mayor Obregón con todo el parque y equipajes y sigue aumentándose el número de enfermos y ha venido de La Jagua el capitán López también enfermo. Se pidió una noticia de las bestias que se necesitan para la marcha en los batallones, parque y comisaría. Nada se sabe del mayor Obregón después de su salida.

Instrucción. La misma.

Subsistencia. La misma.

Movimiento. Salió a las 10 de la mañana una partida de Caballería [f. 265r] al mando del ciudadano Silvestre Sosa con destino a Muelita a recoger aquella gente que no se ha presentado.

Ocurrencias. Han salido de alta ocho Rifles. Murió uno y otro de Pamplona. Le despachó un posta para el señor comandante Córdova con el duplicado para el señor coronel Montilla llamado Lucas Padilla. Han entrado ocho enfermos del hospital venidos del Chaparro pertenecientes al batallón de Flanqueadores.

Instrucción. La misma.

Subsistencia. La misma.

Movimiento. Ninguno.

Ocurrencias. Llegó la partida que fue a Muelita con el ciudadano Sosa. Se han presentado algunas mujeres más y un hombre. Pasó revista de municiones el batallón Rifles. Aún no se sabe nada del mayor Obregón.

Instrucción. Se han ejercitado los cuerpos. De mañana por compañías y en la tarde por batallones.

Subsistencia. La misma.

\section{5}

Movimiento. Marchó una partida de 20 hombres de Caballería que vino conduciendo 60 reses a reunirse a su cuerpo al Chaparro.

Ocurrencias. Se castigaron ocho soldados de Rifles que se encontraron ocho robando en los conucos, con 25 palos cada uno. Se pidió ganado al Chaparro al señor coronel Carmona por estarse acabando el que hay. Se supo por el mismo señor coronel que el señor coronel Montilla se hallaba en San Antonio situado en la costa del Magdalena. No se sabe cuántas son las tropas que allí tiene, ni se asegura ser cierta esta noticia.

Instrucción. La misma.

Subsistencia. Carne y raíces.

Movimiento. Ninguno.

[f. 265v] Ocurrencias. Se supo a las 8 de la mañana que la detención del mayor Obregón con los efectos consistía en haber quedado en Chiriguaná recogiendo víveres. Ha llegado una canoa en que fueron dos hombres a saber de él y dar esta noticia. En el instante se pidieron las noticias de las bestias 
que necesitaban los cuerpos para la marcha. Se nombró al ciudadano Silvestre Sosa, comisionado de los pueblos por [la] cordillera desde aquí hasta San Bernardo y hasta donde vaya adelantando sus marchas la División. Se le han dado las instrucciones y se le previno que recoja todo el ganado y bestias que se pueda y deposite aquel en Simaña en un buen potrero. También se le dio orden para formar una compañía en cada uno de los pueblos para custodia y guarnición de aquel a que pertenezca, y para disponer de ellas en favor de otra operación cuando se necesite. No se ha sabido nada hoy del enemigo y se hacen los mayores esfuerzos por saber.

Instrucción. Se ejercitan las tropas a mañana y tarde.

Subsistencia. La misma.

Movimiento. Ninguno.

Ocurrencias. Llegó al puerto de la Ciénaga el parque y equipajes y se condujeron al pueblo en hombros de la tropa. En el momento se dio orden para que se pusiera todo listo para marchar al amanecer. Hubo tres altas en el batallón de Rifles.

Instrucción. La misma.

Subsistencia. La misma.

8

Movimiento. A las 10 de la mañana se puso en marcha la División con dirección al Valle Dupar. Marchó por sabana y cejas de monte dos leguas y media después de las cuales [f. 266r] llegó al Hato del Escoriado. Se camparon los cuerpos en la sabana en columnas. Los enfermos de cada cuerpo se pusieron en una casa. El parque se campó a la derecha del batallón de Rifles con la correspondiente guardia.

Ocurrencias. Se murieron en el tránsito un enfermo del batallón Pamplona y seis casi de repente estando sanos perfectamente. Se atribuye este deceso al fuerte sol que hace. En este lugar hay una casa grande vieja en la que se pueden campar 500 hombres y seis pequeñas donde se pueden alojar 300. El hato está abandonado pero hay todavía como 200 bestias aunque no hay ningún ganado. Encontramos en este hato 25 enfermos que vienen de la $2^{\mathrm{a}}$ columna con un oficial para conducirlos a Chiriguaná y se detuvieron todos al siguiente día en el cual se remitieron.

Instrucción. La misma.

Subsistencia. Carne fresca.

9

Movimiento. Se puso en marcha la División a las 7 de la mañana y a las cuatro leguas del camino llegó al Hato del Chaparro. Se le dio cuarteles en las casas del pueblo. Buen camino por sabanas secas.

Ocurrencias. Nos reunimos en este hato con la $2^{\mathrm{a}}$ columna. Se racionó la tropa y nos preparamos a marchar al amanecer por lo que se remontó la Caballería y parque. En este sitio se pueden alojar 2.000 hombres.

Instrucción. La misma. 
Subsistencia. Carne fresca en abundancia.

10

Movimiento. Se continuó la marcha a las 8 de la mañana. Ha venido una descubierta compuesta de la $1^{\text {a }}$ de Rifles, después la Caballería, en seguida el resto del batallón, luego Pamplona y el parque, y Flanqueadores cubriendo la retaguardia. A las cinco leguas y media de marcha y a las cuatro de la tarde llegamos al pueblo de Becerril [f. 266v] de donde pasamos a dormir a la sabana, campando a Rifles a la derecha, en el centro Pamplona y a la izquierda Flanqueadores.

Ocurrencias. En el paso del río antes de llegar al pueblo se encontró nuestra descubierta con una avanzada enemiga que hizo fuga. No se pudo aprehender ninguno por lo espeso de los montes. Se cubrió el campo y pasamos la noche sin novedad.

Instrucción. La misma.

Subsistencia. La misma.

11

Movimiento. A las 7 de la mañana se continuó la marcha llevando la caballería en la vanguardia. Marchamos dos leguas de buen camino y llegamos a la sabana de a las 12 del día. Se campó la tropa en el mismo orden del día anterior y pernoctó la División.

Ocurrencias. Ninguna.

Instrucción. La misma.

Subsistencia. La misma.

\section{2}

Movimiento. Se siguió la marcha a las $7 \frac{1}{2}$ de la mañana y caminamos tres leguas al cabo de las cuales llegamos a una ciénaga a las 121/2 del día. Se campó la división en columnas para pasar así la noche. Buen camino por sabanas y cejas de monte pero hay poco pasto para las bestias. Se aprehendieron dos hombres que vinieron a revisar el campo que nosotros dejamos este día. El señor comandante después de haberlos confesionado, los hizo matar por haber resultado enemigos declarados.

Ocurrencias. Se dio la orden para que marchara la Caballería y Flanqueadores a media noche a ocupar el pueblito, donde dicen que se halla el enemigo. Llovió desde las 7 de la noche hasta las 2 de la madrugada. La tropa hizo ranchos para pasar la noche.

Instrucción. Ninguna.

Subsistencia. Ninguna por no haber qué comer en este lugar.

\section{[f. 267r] 13}

Movimiento. A las dos de la mañana marchó la $2^{\text {a }}$ columna con el objeto prevenido ayer. A las 7 de la mañana siguió el resto de la División hasta el pueblito en donde llegamos a las 12 del día después de 21/2 leguas de marcha. Se alojó la tropa en las casas y se tomaron las medidas necesarias para asegurar el cuartel. 
Ocurrencias. La Caballería y Flanqueadores al entrar a este lugar [se] encontraron con el enemigo en número de 230 hombres: 80 de Caballería y el resto de Infantería siendo 40 de aquellos españoles y estos de los Colorados de Ocaña ${ }^{14}$ y demás pueblos del Valle, Santa Marta. El enemigo huyó y nuestra Caballería se echó sobre él por el camino de la derecha del pueblo y la Infantería por el de la izquierda. Como a una hora de marcha mandó el comandante de la Caballería el parte del señor coronel Carmona de que el enemigo se había parado en formación al pasar con puentes. El coronel Carmona siguió con la Infantería pero al llegar al puente ya se había retirado el enemigo. Se remontó allí nuestra Caballería y siguió las huellas, los alcanzó y fue matando e hiriendo enemigos hasta dos leguas más allá del pueblo del Fuerte. La victoria sobre esta pequeña fuerza fue casi completa. Le mataron ocho hombres, se hirieron sobre 30 y el enemigo que se salvó fue amparado del espeso monte en que fue destrozado. Se tomaron 18 latones, 30 lanzas, sobre 25 carabinas, 40 caballos ensillados. Se devolvió nuestra Caballería al pueblo de Bonda donde nos reunimos con todos los cuerpos.

Ocurrencias. Inmediatamente que llegamos al pueblito se mandaron ocho partidas de Infantería por los conucos inmediatos a tomar algunas mujeres y vecinos que nos dieran noticia del enemigo. Una partida que salió al mando del capitán White [se] encontró con unos indios flecheros que le mataron un sargento y lo hirieron a él. No se pudo aprehender ninguno de estos porque al disparar la flecha toman el monte y huyen. La partida del capitán León aprehendió dos hombres y fueron matados inmediatamente que declararon, por orden del señor comandante general. Este pueblo y todos los demás del territorio son muy enemigos de la causa.

[f. 267v] Instrucción. Ninguna.

Subsistencia. Marranos y cabras.

14

Movimiento. A las ocho de la mañana siguió la División con la Caballería en la vanguardia y al cabo de tres horas de marcha llegamos al pueblo del Tuerto, habiendo pasado por el del Jobo. En este pueblo se pueden alojar 1.500 hombres. No hay qué temer y los pueblos son muy viejos y miserables. La jornada es de tres leguas y media.

Ocurrencias. No se ha presentado nadie en el pueblo. La tropa se campó a la derecha de él en la sabana donde había agua porque él no la tiene; pusimos una avanzada en el pueblo y se cubrió el campo. Murió el teniente Mora y dos soldados de Rifles.

Instrucción. Ninguna.

Subsistencia. Carne muy poca.

15

Movimiento. Marchó la División a las 8 de la mañana y después de dos leguas y media de camino llegamos al Hato de Paja de Conejo en donde se campó la Caballería en la sabana y la Infantería en las casas a excepción del batallón

${ }^{14}$ Guerrillas fieles a la causa española que realizaron constantes ataques a las huestes patriotas en la provincia de Ocaña. 
Flanqueadores que también se campó en la sabana cerca del parque para que le sirviese de custodia.

Ocurrencias. Aprehendió el ayudante de Caballería un hombre a quien le quitó el sable y el caballo vendiéndoselo por español pero, entrando aquel en malicia al ver un soldado de Caballería con banderola blanca en la lanza, se fugó al monte no habiéndose podido volver a aprehender. Se mandaron partidas con el objeto de aprehender algunas personas pero no se pudo lograr. Se cubrió el campo.

Instrucción. Ninguna.

Subsistencia. La del día anterior.

16

Movimiento. A las seis de la mañana se puso en marcha el señor comandante general con el batallón de Rifles llevando una descubierta de la caballería a la vanguardia y el resto sigue [f. 268r] a retaguardia como a las 121/2 llegaron al pueblo de Diego Pata, el resto de la División llegó a las tres y toda se campó en el pueblo a excepción de Flanqueadores y la Caballería que se camparon en la sabana junto al parque como custodia de él.

Ocurrencias. Se destinaron 14 carabineros al pueblo de Tupes al mando del capitán Martínez a hacer una correría pero los indios en número de más de 100 derrotaron o pusieron en dispersión las partidas y vino hasta Diego Pata a dar parte al señor comandante general. Este hizo poco caso de los indios, y reforzando la misma partida la destinó al pueblo de La Paz a otra correría pero tampoco pudo llegar porque el enemigo emboscado en un conuco le hizo fuego y le hirió un carabinero. Los indios de los Tupes vinieron en persecución de la partida hasta el cuartel y fue preciso poner en acción todo el batallón de Rifles para ponerlos en fuga. Nos hirieron dos soldados con un flechazo y un fusil de nuestra misma tropa se fue del seguro e hirió gravemente otro del mismo cuerpo. Nosotros matamos un indio y herimos tres o cuatro. Se cubrió el campo con avanzadas dobles y la tropa durmió formada en cuadro apoyadas a un corral. Este pueblo lo hayamos solo, tendrá 30 casas y no hay pasto. Inmediatamente mandó el señor comandante general a quemar el pueblo de los indios en castigo de la osadía que tuvieron de venir a atacar nuestro cuartel.

Instrucción. Ninguna.

Subsistencia. Ninguna.

17

Movimiento. Con el mismo orden anterior marchó el señor comandante general y a la una del día llegamos con el batallón de Rifles al Hato de Galambao después de tres leguas de marcha, el resto de la División llegó un poco después y campó formando cuadro alrededor de las casas de la hacienda. Ocurrencias. En este lugar aprehendimos tres mujeres y un hombre y a poco rato se presentó otro voluntario. El señor comandante general tomó informes de este, sobre la situación, estado y [f. 268v] operaciones del enemigo y lo mandó al Valle Dupar como espía a ver y examinar el lugar a las 7 de la noche volvió con la razón de que estaba ya abandonado, y que solo había unas 
familias en el convento de Santo Domingo con el Reverendo Padre Guardián. La Caballería se campó en una hacienda inmediata a donde se llevaron también las bestias del parque. El camino es regular y casi todo monte.

Instrucción. Ninguna.

Subsistencia. Carne.

18

Movimiento. El señor comandante general con 16 hombres de Caballería se adelantó a las 8 de la mañana a llegar al Valle cuya distancia no es más que legua y media. Llegó en poco tiempo y previno los cuarteles en la plaza para la División que quedaba a retaguardia con el coronel Carreño.

Ocurrencias. Llegó la División a las 11 al Valle Dupar y se acuarteló inmediatamente se arreglaron los hospitales y la casa del parque. El pueblo lo encontramos casi solo con la gente que se hallaba reunida en el convento. Los soldados de Rifles y Flanqueadores hicieron algunos robos de poca consideración y, aunque se averiguó escrupulosamente, no se pudo saber quiénes fueron los ladrones. Se registraron sus maletas, se encontró alguna ropa y se entregó a sus dueños conforme fueron apareciendo. Este pueblo es grande de más de 3.000 vecinos y con más de 300 casas pero sus habitantes son muy godos.

Instrucción. Ninguna.

Subsistencia. Ninguna por no haber quien dirija el lugar donde se encuentran los ganados y por ser estos cimarrones.

Movimiento. A las 9 de la mañana se puso en marcha el batallón Rifles y 25 hombres de Caballería al mando del señor coronel Carreño con dirección a San Juan y Badillo a donde se dice estar el enemigo. Lleva órdenes de sorprenderlo, destruirlo y perseguirlo. En la misma hora salió el capitán Martínez con otra partida de Caballería hacia el Playón a 7 leguas de distancia con el objeto [f. 269r] de recoger bestias y ganados.

Ocurrencias. Se han presentado algunos hombres y mujeres. Se tomaron providencias para sacar las familias de los montes. Se mandaron partidas de todos los cuerpos a recoger y traer cabras para la tropa.

Instrucción. Se ejercitaron los batallones Pamplona y Flanqueadores en sus cuarteles.

Subsistencia. Carne de la traída por las partidas de los cuerpos.

Movimiento. Ninguno.

Ocurrencias. Se han recibido comunicaciones del señor coronel Montilla, almirante Brion y comandante Córdova, dicen que toda la provincia de Cartagena está ya libre y el enemigo solo reducido a las trincheras de la ciudad, teniendo el cuartel general patriota en Turbaco. Se han despachado otras para el Ministerio de Guerra. Ha venido un espía que se mandó sobre el enemigo y dice estarse reunido este en San Juan. Se sigue presentando gente de la ciudad. 
Instrucción. La misma.

Subsistencia. Para racionar la tropa de carne, se han mandado partidas de Infantería a coger ganado a bala y se hace racionado de plátanos comprados a los vecinos.

Movimiento. Ninguno.

Ocurrencias. Avisó el capitán Martínez que no había cogido ganado ni bestias $\mathrm{y}$, que aunque había, no se podrían traer por ser monte todo. Se le dio un práctico para ir a Pueblo Nuevo donde dicen que el ganado es manso y se puede traer alguno. Se trabaja en componer los aperos del parque y se está trayendo ripio o cepa de plátano para hacer sudaderos. Nada se ha sabido del señor coronel Carreño.

Instrucción. La misma.

Subsistencia. La misma.

Movimiento. Ninguno.

Ocurrencias. Llegó el capitán León con una partida de la columna del señor coronel Carreño. Dice que en Badillo encontraron una partida enemiga y que luego que esta hizo fuego a la descubierta [f. 269v] que él llevaba, cargó sobre ella y la puso en fuga. Se tomó dos bestias ensilladas, dos carabinas y algunas otras cosas. Que en San Juan no han hallado a nadie y que la columna llegará mañana. Esta ha venido por el camino de Corral de Piedra a Patillal. Allí tomaron la familia del coronel Daza y un español, y tomaron el camino real en los Corazones a una legua de aquí. Llegó también el capitán Martínez, trajo once reses, nueve caballos y ocho mulas. Se sigue presentando la gente del pueblo.

Instrucción. La misma.

Subsistencia. Carne y plátano.

23

Movimiento. Ninguno.

Ocurrencias. Llegó el señor coronel Carreño con el batallón Rifles a las 10 del día, trajo 11 hombres presos del país, 54 mulas, 11 yeguas y 18 caballos, y se acuarteló el batallón. Llegó el ciudadano Antonio Guillén, desertado de los enemigos, dice que en Rio Hacha hay 270 hombres venidos de Bailadores. El espía que se mandó a donde el señor coronel Carreño para que lo impusiera de todo no ha vuelto. Se cree que se habrá escondido o pasado a los enemigos. Instrucción. La misma.

Subsistencia. La misma.

Movimiento. Ninguno.

Ocurrencias. Los puntos avanzados han dado parte sin novedad. Se han mandado dos partidas de Rifles a recoger todos los hombres que se encuentren en los sitios inmediatos. Mañana saldrán partidas de Pamplona y 
Flanqueadores con el mismo fin. Han salido un cabo [y] 4 soldados de Rifles a traer 20 reses.

Instrucción. La misma.

Subsistencia. La misma.

Movimiento. Ninguno.

Ocurrencias. Han salido las partidas de Pamplona y Flanqueadores con el mismo objeto que se indicó ayer. Han venido todas [f. 270r] las partidas y han salido 102 hombres de todas clases, la de Rifles trajo 64, la de Pamplona 28 y la de Flanqueadores 10, y además ha traído la de Pamplona dos soldados prisioneros cogidos en el Hato de Galambao. Se justificó ser estos dos hombres de las tropas Coloradas de Ocaña que siguen a los españoles y se sorteó uno para ser pasados por las armas inmediatamente. Se dio la orden para ponerse en marcha la División a la una de la noche del día siguiente y se previno todo para el efecto. Llegó la partida que fue a buscar las 20 reses y trajo solo 16.

Instrucción. La misma.

Subsistencia. La misma.

26

Movimiento. A la una de la mañana se comenzó a montar, cargar el parque y hospitales, y esta operación duró hasta las cinco que se emprendió la marcha con dirección a Camperucho. Anduvimos cinco leguas, lleva la División el orden siguiente: a la retaguardia la Caballería y en seguida Flanqueadores, después de este todos los enfermos de la División y los reclutas hechos en el Valle que vienen en las prevenciones de sus cuerpos respectivos. Luego el parque, a su retaguardia Pamplona y detrás de este los equipajes cubriendo Rifles la retaguardia general. Al cabo de las cinco leguas llegamos a un hato que queda a la derecha del camino.

Ocurrencias. Se campó la Caballería y Flanqueadores en la sabana y Rifles y Pamplona en dos casas únicas que había. Se tomó en el tránsito un hombre que iba para el Valle y dice que Pueblo Nuevo está abandonado con otros enfermos de poca importancia. A la derecha del camino antes de llegar a este hato está el de Maldonado a una legua de distancia. En el sitio del campamento no habíamos hallado a nadie pero parece según la huella que se han ido esta mañana.

Instrucción. La misma.

Subsistencia. Carne.

27

Movimiento. Se puso en marcha la División a las 7 de la mañana con [f. 270v] el mismo orden anterior y marchamos tres leguas por sabanas y cejas del monte al cabo de las cuales llegamos al Hato de Agua Blanca.

Ocurrencias. Pasamos por Pueblo Nuevo a la hora de marcha. Estaba solo, no tiene malas casas y estas serán 80. Legua y media antes de llegar al campamento encontramos una quebrada crecida y nos detuvo bastante tiempo 
por lo torrentoso de sus aguas. Se aprehendió un hombre de este hato y dio algunos informes al señor comandante general. El señor coronel Carmona con una partida de carabineros fue sobre la derecha al Hato de Pedro Becerra en donde tomó 25 caballos y algunas mulas. Encontró también allí un clérigo recién venido de Santa Marta y dio algunas noticias, las que comunicó el señor coronel Carmona al señor comandante general.

Instrucción. La misma.

Subsistencia. Carne.

28

Movimiento. Nos pusimos en marcha a las 7 de la mañana y a las dos de la tarde llegamos al Hato de María Angola después haber marchado tres leguas de sabana y buen camino.

Ocurrencias. Aquí aprehendió el comandante de la descubierta el dueño del Hato y cinco hombres, los que destinó el señor comandante general a la Caballería. Se recogió ganado para llevar porque adelante no hay este renglón sino en el Camperucho. Se tuvo la noticia (dada por un hombre presentado) que sobre el río Sarar había tres frailes españoles con muchas cargas, y se mandaron aprehender con una partida de Caballería mandada por el señor coronel Carmona. Se cubrió el campo.

Instrucción. La misma.

Subsistencia. Carne.

29

Movimiento. A las $71 \frac{1}{2}$ de la mañana se continuó la marcha, a las $2 \frac{1}{2} 2$ leguas pasamos por el Hato del Diluvio donde hay dos casas abandonadas. Seguimos y a la legua llegamos [f. 271r] a Camperucho.

Ocurrencias. Se campó la División en la sabana y los hospitales en las casas. Se aprehendieron los tres frailes con su cargamento, los que fueron traídos por el señor coronel Carmona. Se embargó todo este equipaje y sobre 600 pesos y se puso todo en comisaría, dejando a los frailes solo lo de su uso. Estos venían de Santa Marta a donde habían huido del señor coronel Montilla y volvían creyendo ya todo pacífico con la retirada de éste. Se dio un fraile a cada batallón en calidad de capellán. Hubo dos desertores en Pamplona. Se dio la orden para que se acorten las cargas de equipajes y lleven solo dos los coroneles, una los comandantes y mayores, una para cada dos capitanes y una para tres subalternos. Igualmente se resolvió detenernos en este lugar el día de mañana para coger ganado porque más adelante no lo hay.

Instrucción. Ninguna.

Subsistencia. Carne.

Movimiento. Ninguno.

Ocurrencias. Salió una partida de 30 hombres de Caballería a coger caballos y se mandó otra a recoger ganado. Se pusieron con la madrina de Caballería todas las bestias en pelo. Se dio la orden de marchar para el amanecer del día siguiente. Se cogieron sobre 200 reses. 
Instrucción. Ninguna.

Subsistencia. La misma.

\section{1}

Movimiento. A las 6 de la mañana se puso en marcha la División por el orden siguiente: Rifles a la vanguardia con su equipaje y diez cargas de parque en el centro, siguió Pamplona lo mismo y luego Flanqueadores con su equipaje y diez cargas de parque en su vanguardia y después la Caballería con los caballos y ganados. Marchamos cuatro leguas y llegamos a la sabana del Tábano después de haber pasado por el alto de las Minas [f. 271v] y una montaña muy pedregosa de más de una legua.

Ocurrencias. Aquí se campó la División y pernoctó. Se desertaron cuatro hombres de Pamplona. Desde las cuatro de la tarde empezó a llover hasta media noche. Se cubrió el campo.

Instrucción. Ninguna.

Subsistencia. Carne.

\section{Agosto $1^{\circ}$}

Movimiento. Marchó con el mismo orden la División a las 6 de la mañana con dirección a partir la Montaña Grande de Santa Marta y atravesar el Cerro de San Antonio. El señor coronel Carreño se adelantó con una compañía de Rifles a tomar el pueblo de Guayacando. Efectivamente nosotros llegamos a las dos de la tarde y ya hayamos ocupado el pueblo por él. Marchamos cinco leguas por montaña todo y mal camino. Se sabe por los prácticos que esta montaña tiene sobre 40 leguas y toda de muy mal piso y sin pasto en las más de las dormidas.

Ocurrencias. Llegó la vanguardia al pueblo a las 2 de la tarde y estuvo llegando la retaguardia a las 8 de la noche habiéndose quedado el ganado y Caballería en la montaña. El batallón Rifles y el gran parque siguieron una legua más a pasar el río Ariguaní pero no lo pudieron verificar por estar muy crecido. Se camparon a la orilla, y Pamplona y Flanqueadores con sus hospitales, parque y equipaje se quedaron en el pueblo. Aquí se compraron cuatro conucos de maíz para poner las bestias. Se compró igualmente mucho maíz tierno y seco, yuca, batatas y caña para la tropa. Se aprehendieron en este pueblo algunos indios, un español y unas mujeres pero no dicen nada de particular. Se aprehendió también un hombre con una carga de víveres y géneros que acaba de llegar procedente de Santa Marta. Los géneros se embargaron y pusieron en comisaría. Este trae una carta que dice que Morillo ha mandado parlamentario a [f. 272r] Su Excelencia el Libertador y ha hecho suspensión de armas en todo Venezuela. Que de Santa Marta han mandado también a los señores almirante [Luis Brión] y Montilla, y que los diputados de nuestro Congreso que fueron a Londres han pasado a España a tratar con las Cortes.

Instrucción. Ninguna.

Subsistencia. Carne. 
Se pasó todo este día pasando el río que ya había bajado y se campó la División en la ribera derecha después de haberse racionado por cuatro días.

3

Movimiento. A las tres de la mañana se empezó a cargar y prevenirse para la marcha y a las 6 ya estaba todo listo; se tomó a esta hora el camino el que es todo de montaña muy cerrada, al cabo de tres leguas de marcha llegamos a la sabana del Ángel habiendo pasado por la de San Antoñito.

Ocurrencias. En la sabana del Ángel se acamparon Rifles, Pamplona y parque, y en la otra Flanqueadores, Caballería y ganados. A las cuatro de la tarde cayó una fuerte lluvia que duró hasta las seis. Se remontaron los parques y hospitales, reponiendo las bestias que se cansaron en la jornada de hoy. Se ha desertado un hombre de los aprehendidos en María Angola y doce vallenatos. Se cubrió el campo.

Instrucción. Ninguna.

Subsistencia. Ninguna por estar racionados los cuerpos.

\section{4}

Movimiento. A las seis de la mañana se puso en marcha la División llevando adelante la $1^{\mathrm{a}}$ compañía de Rifles abriendo el camino. Marchamos cinco leguas por montaña al cabo de las cuales llegamos a los Cañitos en medio del monte en donde nos campamos sin haber pasto, y habiendo mandado la $1^{\mathrm{a}} \mathrm{de}$ Rifles un poco más adelante.

Ocurrencias. Llegaron cansadas algunas bestias del parque y hospitales, las que se repusieron con las de la Caballería y mujeres. Llovió un poco y pernoctó la División.

[f. 272v] Instrucción. La misma.

Subsistencia. La dicha.

Movimiento. Siguió la División a las 6 en el mismo orden y después de cinco leguas de camino llegamos a Ciénaga de Santo Toribio donde hay una pequeña sabana. Aquí se campó la División.

Ocurrencias. El camino es todo monte. Llegó un soldado enemigo del Valle Dupar como parlamentario trayendo unos pliegos del gobernador de Santa Marta y comandante Esteban Díaz, proponiendo en ellos que se haga suspensión de armas para tratar los medios más adaptables de quedar en paz. Incluye dos proclamas, una del Rey y otra de [Pablo] Morillo y anuncian que la misma proposición han hecho al señor coronel Montilla. Estos pliegos eran conducidos por un oficial con cuatro soldados; este llegó hasta Ariguaní y tuvo temor de pasar hasta donde se hallaba la División y lo mandó con un soldado. El señor comandante general contestó inmediatamente con el mismo parlamentario "que sus operaciones continuarán hasta que tenga orden expresa del general en jefe del Ejército Libertador de quien depende". Se mató todo el ganado y se racionó toda la tropa por cuatro días. Se repusieron las bestias de los parques cansadas en este día. 
Instrucción. Ninguna.

Subsistencia. La dicha.

6

Movimiento. A las cinco de la mañana se movió la División, marchó cinco leguas y se campó entre la montaña.

Ocurrencias. Los batallones Flanqueadores y Pamplona se quedaron un poco más atrás en un paradero. Se repusieron las bestias cansadas. El camino tiene mucho barro. Se han muerto cinco hombres de los batallones.

Instrucción. Ninguna.

Subsistencia. Ninguna.

Movimiento. A las cinco de la mañana se puso en marcha la División [f. 273r] por montaña y a las dos de la tarde llegamos al río Sapayán después de cuatro leguas de camino.

Ocurrencias. El río estaba muy crecido y tuvimos que hacer dos puentes para pasar. Pasó todo el batallón Rifles y el parque general y se camparon. El batallón Pamplona y el de Flanqueadores quedaron del otro lado para pasar muy de mañana pues era ya de noche y no podía pasar. El camino es muy malo.

Instrucción. Ninguna.

Subsistencia. Ninguna.

\section{8}

Movimiento. Siguió a las 5 de la mañana todo lo que había pasado el río ayer y quedó el mayor Obregón encargado de hacer pasar y conducir todo lo que faltaba. Marchamos por un agua sal más de media legua y dos leguas más todo de monte al cabo de las cuales llegamos al Hato de Sapayán a las 10 del día.

Ocurrencias. Aquí hemos encontrado cuatro hombres del Hato y algunas mujeres muy sencillas y patriotas. Se mató ganado, se racionó este batallón y se guardó para los otros. Estos empezaron a llegar a las tres de la tarde y han estado llegando hasta las 9 de la noche pero siempre han quedado muchos atrasados y casi todo el parque a causa del muy mal camino y de las bestias cansadas. Se ofició al comandante y cura del cerro de San Antonio para que previnieran 3.000 raciones para mañana. Salió el capitán Coca con pliegos para el señor coronel Montilla. El señor comandante general le propone que le diga en qué punto se pueden ver para hallarse, y le encarece mucho lo interesante de esta entrevista. Se mandó un comisionado a buscar más ganado. Se han muerto entre ayer y hoy diez y siete hombres de los hospitales.

Instrucción. Ninguna.

Subsistencia. Carne y maíz comprado a los vecinos de este Hato.

9

Movimiento. Salió una partida de Caballería a recoger bestias al mando del comandante Calderón. 
Ocurrencias. Ha llegado todo lo que se había atrasado en la marcha [f. 273v] de ayer, llegó la partida de Caballería y trajo las bestias caballares. Llegó igualmente el comisionado que fue a buscar ganado y trajo alguno. Se socorrieron los batallones Pamplona y Flanqueadores con algún dinero para comprar pan. Llegó la contestación del cerro de San Antonio. Dicen los alcaldes que estarán listas no solo las 3.000 raciones sino todas las más que se necesitan, y que están prontas cien embarcaciones para lo que pueda convenir. El capitán Coca, oficial que por ser hombre venido de Ocaña, se sabe que el general Bolívar derrotó completamente a Morillo cerca de Cúcuta y que las guerrillas de Bataller entraron en Chiriguaná y tomaron prisioneros al capitán Sosa y al capitán de Rifles que había quedado allí, habiendo salido aquel herido y ocupa aún la guerrilla aquel pueblo.

Instrucción. Ninguna.

Subsistencia. Carne y maíz.

Movimiento. Ninguno.

Ocurrencias. Se ha preparado todo para marchar mañana.

Instrucción. Ninguna.

Subsistencia. La misma.

11

Movimiento. A las 5 de la mañana marchó la División por muy mal camino y a las 12 del día llegó al sitio del Caimán después de haber marchado cinco leguas de muy mal camino y pasado por el sitio del Peludo.

Ocurrencias. Se prepararon todas las embarcaciones para pasar la tropa al pueblo de San Antonio. Se pasó el parque y hospitales y el batallón Flanqueadores y comisaría. Quedaron solo Rifles y Pamplona con la Caballería para seguir por tierra. Se recibió oficio del Piñón avisando que a once leguas de allí en el sitio de la Yuca hay 200 hombres venidos de Santa Marta.

Instrucción. Ninguna.

Subsistencia. Carne y maíz.

12

Movimiento. El batallón de Rifles y Pamplona siguieron por [f. 274r] tierra para el Piñón con la Caballería a las 8 de la mañana y un resto de enfermos y los equipajes siguieron por agua para San Antonio habiéndolo hecho antes el señor comandante general.

Ocurrencias. Llegamos al cerro de San Antonio a las 11 y media del día y se hicieron seguir los enfermos y equipajes para el Piñón a reunirse con la columna, se hizo marchar a Flanqueadores con el mismo destino. Se ha empezado a mandar a hacer vestidos para la tropa con los géneros que hay en comisaría. Este pueblo es muy patriota y hay mucho qué comer. Está situado a orilla del Magdalena y tendrá como cien casas.

Instrucción. Ninguna.

Subsistencia. Carne y pan. 
Es copia fiel.

San Antonio, agosto 12 de 1820.

Jacinto Lara". 